\title{
Library Data Labs: using an agile approach to develop library analytics in UK higher education
}

\section{Structured abstract}

Purpose. This paper gives an overview of the Jisc and HESA Library Data Labs project and its outputs. This collaboration involved bringing together cross-institutional library teams to produce proof of concept data-visualised dashboards using library analytics data that could be made available to others via the Heidi Plus service.

Design/methodology/approach. The teams used an agile approach, which adapted the agile methodology for non-technical and disparate team members. The key agile elements were followed, including the Scrum approach, whereby teams had a product owner, several development team members, a data wrangler and a scrum master. Many of the dashboards took inspiration from some of the earlier Jisc work on library analytics.

Findings. A wide variety of proof of concept dashboards were created addressing a range of library issues. These fell into two main categories for the cross-institutional teams: comparing the SCONUL annual statistics results against the National Student Survey (NSS) data, and collection management and analysis.

Research limitations/implications. Some of the HESA data were potentially sensitive. In effect this created a walled garden as some of the data were not designed for sharing. Furthermore, the data that the Jisc team used was restricted by publisher agreements, meaning that specific institutions usage could not be identified to others.

Originality/value. The paper provides insight into the Library Data Labs project and discusses a number of implications from the outcomes of the project. These are now being investigated by HESA, Jisc and individual institutions.

\section{Key words}

Library usage, analytics, student attainment, academic libraries, undergraduate students, achievement, visualisations, business intelligence

\section{Introduction}

Library analytics can be described as "transactional data on catalogue searches, items check-outs, log-ins to online resources and services, swipes through the entrance gates; manually collected statistics on space usage, student satisfaction, [and] external visitors to the library" (Showers, 2015a, p.xxvi). These data are used to drive decisions and services in a number of areas in the library such as collection management, demonstrating value and impact and meeting user requirements.

In the UK, Jisc has been involved in this area since the launch of the Jisc Activity Data programme in 2011 (Jisc, 2011). A number of different initiatives have followed, the latest, Library Data Labs (Jisc 2017a), was the third in a series of development cycles in the Jisc and Higher Education Statistics Agency (HESA) Business Intelligence project. It followed the successful format of two previous cohorts, which involved working with university strategic planners. In addition to producing new 
business insights with the data available, the aim of those cohorts was to produce data-visualised dashboards that could be made available to others via the Heidi Plus service, the business intelligence service for UK Higher Education (HESA, n.d.). This project provided an opportunity to libraries to explore whether the concept could be replicated in a library context using library analytics data with the aim of producing library-specific insights.

This paper will set out the current literature in the UK, setting this against the wider literature regarding the development of library analytics. It will describe and explain the agile project methodology used in the library labs project before detailing the project outcomes. The paper will discuss the implications of the Library Data Labs project for UK higher education institutions. Wider implications for Jisc in respect to its library support services, such as the use of visualisation in Jisc's Journals Usage Statistics Portal (JUSP) (Jisc, n.d.a) and Jisc Collections negotiations and licensing will also be discussed. Finally, the paper will conclude with some suggestions for further work that could be undertaken by Jisc and institutions.

\section{Library analytics in the UK}

There has been an interest in the relationship between library use and undergraduate attainment stretching back to the 1960s and 1970s (Barkey, 1965; Lubans, 1971; Mann, 1974). However, there is little evidence of more research in this area until the turn of the century (Stone and Ramsden, 2013). More recent studies investigated the relationship between university library usage and undergraduate student outcomes (De Jager, 2002a; 2002b; Emmons and Wilkinson, 2011; Han et al., 2011). However, the earlier literature does not take electronic resource information use into account, which for e-journal use, has reached a tipping point in recent years (Johnson and Luther, 2007). Indeed, De Jager suggested that further investigation was necessary to discover where electronic resources play a part in achievement. Further research has considered the relationship between library value and impact on research and learning (Oakleaf, 2010; Tenopir and Volentine, 2012). These studies have found that the library supports key academic research activities and can thus be considered to make a vital contribution to university value. More recently, work around standards have greatly contributed to the discipline of library analytics (Poll and Payne, 2006; Poll, 2012; De Jager, 2017).

In the UK, Jisc has funded a number of studies in this area. Much of this work was based on an original study of non-use of library resources, including e-resources at the University of Huddersfield in 2009 (White and Stone, 2010). In 2011, the Jisc funded Library Impact Data Project (LIDP) at the University of Huddersfield investigated the hypothesis that "[ $t$ ]here is a statistically significant correlation across a number of universities between library activity data and student attainment" (Stone and Ramsden, 2013). The research demonstrated this relationship using data from 33,074 undergraduate students across eight UK universities. In parallel, research was being conducted in Australia (Cox and Jantti, 2012) and the US (Soria et al., 2013). All three projects were the first to include e-resource usage as part of the data and found similar results in the correlation/statistical significance of library use and student attainment. However, all projects pointed out that the relationship was not a causal one. More recently, this research was supported by De Jager et al. at the University of Cape Town (De Jager et al., 2017). In addition Bowles-Terry (2012) reported a positive correlation between higher grade point average and information literacy instruction. The projects have been in regular contact with each other and have presented together on a number of occasions (Oakleaf et al., 2013; 2017).

Further funding was provided for LIDP2, which sought to dig deeper into the data to investigate the relationship between demographic characteristics, such as age, gender and ethnicity (Stone and 
Collins, 2013), discipline (Collins and Stone, 2014) and retention with undergraduates' use of academic libraries. This research built on earlier studies in these areas (Cox and Jantii, 2012; Soria et al., 2013; Nackerud et al., 2013). In the UK, the University of Huddersfield has continued its work on library analytics, which is now concentrated on increasing library usage among the groups identified as having the lowest use (Stone et al., 2015) and using ethnographic research methods to understand the story behind LIDP (Sharman, 2017).

At the end of the LIDP2 research, Jisc and the University of Huddersfield undertook a survey of UK library directors to gauge their appetite for a potential shared data-analytics service. $96 \%$ of those that replied wanted automatic provision of analytics, which would demonstrate the relationship between library usage and student attainment within their institutions. $94.6 \%$ were also interested in benchmarking their data against other institutions. Furthermore, $87.7 \%$ were interested in the richer set of data investigated by LIDP2 (Showers and Stone, 2014; Showers, 2015b, p.15). As a result, Jisc funded a further project, the Library Analytics and Metrics Project (LAMP), which highlighted the lack of tools and services for libraries to exploit library analytics data and explored the potential of a shared analytics service for UK academic libraries. The prototype LAMP architecture was built around a series of APIs to deliver data to its own dashboard. However, at the time it proved difficult to scale the project to a national level. However, the project did feed into Jisc's work around learner analytics (Jisc, 2017b).

In 2016, the business intelligence project, a joint project between Jisc and the HESA to develop a business intelligence shared service for UK education, launched Library Data Labs. The project worked with UK academic libraries "to explore the possibilities of using and analysing library data in conjunction with HESA data" (Jisc, 2017a). The project's' Analytics Lab toolset, based on Tableau and Alteryx, offers new opportunities to scale the data and to produce visualisations and dashboards, which can be embedded into other services.

The project ran over a 12 week cycle from mid-July to the beginning of October 2016. It was made up of five cross-institutional teams from 23 individual university libraries, totalling 29 participants. There was also a team made up of Jisc staff, which was formed to inform Jisc service enhancement and national negotiations undertaken on behalf of the sector.

\section{Methodology}

The five teams used the same agile approach used successfully by the previous two cohorts, which adapted the agile methodology for non-technical and disparate team members. The key agile elements were followed, including the Scrum approach, whereby teams had a product owner, several development team members and a scrum master. One customisation was the inclusion of a 'data wrangler' from the Centre for Educational Technology, Interoperability and Standards (Cetis), providing support for sourcing and gathering data. The product owner had responsibility for setting the vision for the team and therefore had overall responsibility and oversight of user story development i.e. determining the questions that the teams needed or wanted the data visualised dashboards to answer. Team members had responsibility for creating the dashboards, while the data wrangler supported any data requirements, whether they were from HESA or sourcing other data from the web, such as open data sets. The scrum master's responsibility included supporting the team through the agile process. For example, handling any impediments the team had and liaising centrally with other teams' scrum masters and HESA.

In line with the scrum methodology, teams followed the sprint approach with an initial face-to-face planning meeting. User stories were generated at this point. However, as commitment from team members was limited to one or two days per week, a sprint covered a four week period rather than 
the normal two weeks. The next two face to face meetings after the first and second sprint also included a retrospective review of the previous sprint. This process determined which of the tasks that had been agreed previously by the team had been achieved and could therefore be signed off, which still required further effort or which should be abandoned because they were no longer viable or relevant. The next sprint's planning repeated the activity of the first meeting as any upcoming tasks were generated or carried forward from the previous sprint. Thus the tasks for the next sprint were set.

Meetings in between the face-to-face meetings were held virtually via Skype, video conferencing software or telephone. The format for these days or meetings was typically an initial call in the morning where the team would agree the tasks for the day for each team member. The team would spend the day working on those tasks, after which, the team would reconvene online and provide a progress update. The morning meeting was also an opportunity to raise any issues with the scrum master and where possible, a response could be given within the same day.

Across the 12 weeks, the key activities were user story development and refinement; data analysis to see what the potential sources were and any issues in gathering the data; fulfilling data orders to HESA; exploring the Tableau environment; dashboard development and refinement; and finally publishing the dashboard. As an iterative process, these activities were at times overlapping.

The project culminated with a showcase event where all six teams presented their dashboards to each other and an expert panel from HESA, Jisc and the Society of College, National and University Libraries (SCONUL). The expert panel fed back on each teams' dashboards with HESA giving an indication on the potential for the delivery of each dashboard via HESA's Heidi Plus service. The entire audience also provided feedback using a RAG (Red, Amber, Green) approach, providing an indication of community interest in using the dashboards.

\section{Project outcomes}

Given the pool of library and library-related data available to teams, and the potential for duplication, user stories were shared in the early stages of the project to ensure there was no overlap in the questions being addressed. In total, 23 unique user stories were created by the five external teams, with a further four by the Jisc-only team. As a result, a wide variety of proof of concept dashboards were created addressing a range of library issues. These fell into two main categories for the cross-institutional teams: comparing the SCONUL annual statistics results, which look at trends in library space, resources and staffing across UK HE libraries, against the National Student Survey (NSS) data, which forms part of the quality assurance framework for UK higher education, and collection management and analysis. Many of the dashboards took inspiration from some of the earlier Jisc work on library analytics.

The first dashboard produced a comparison across institutions by subject, using JACS codes (the Joint Academic Coding System) (HESA, n.d.b). A range of characteristics were included for selection that would enable comparison of similar courses and cohorts, including the number of students on the course, percentage of part time, international and mature students in a cohort. As a result, a more like for like comparison of cohorts across institutions was feasible, over which, NSS data could be compared and analysis carried out to look at those institutions scoring well in a given subject. Libraries may well want to understand what those libraries are doing and replicate their initiatives. Primarily the NSS data used throughout was the response to question 16, which asks for the satisfaction rating on whether "library resources and services are good enough for my needs" (SCONUL, 2017a). One caveat here is that the NSS only maps to the top level of JACS and not the 
second level. For example, mapping to Nursing at the JACS second level, will also include results for Subjects allied to medicine.

Two teams looked at specific groupings of SCONUL metrics versus NSS scores. The first team examined the impact of library space on student satisfaction across institutions. Using footfall per full time equivalent (FTE), further analysis was possible with the option to filter by year. This required some data manipulation as the SCONUL return overlaps two years, but the NSS only one. A filter for mission group was included and also an average score line enabled an institution to see where they ranked in a given mission group. Another team explored the 12 NSS questions which will form part of the Teaching Excellence Framework (TEF), which aims to recognise and reward excellence in teaching and learning (HEFCE, 2017). The scores for these questions were pulled into a dashboard with options for filtering on mission group and survey year, with a number of key SCONUL metrics included such as library instruction hours per FTE, number of library staff and library expenditure. Also, a tree diagram was used to visualise the study space analysis by mission group, providing an at a glance view of the ranking of those institutions gaining good NSS results for the "number of study spaces per institution". The same diagram offered the same data but for the SCONUL metric "number of study spaces per FTE" (SCONUL, 2017b) and changes in the rankings were immediately obvious.

Another prototype dashboard would enable a library director to look at key performance indicators (KPIs) using various SCONUL metrics. For example, if a particular institution had a KPI to have a higher than average spend per FTE student on information resources, this can be seen at a glance as the institution could be highlighted in all the related charts against their mission group. Drop down menus allowed the metrics or the institution to be changed easily. The dashboards also showed trends in the results of expenditure over time which helped predict impact of either investment or reduction in spending on student satisfaction.

One team was concerned with analysing the information resources provision within a library using a variety of metrics. The first explored the need to analyse the value of e-journal subscription deals by looking at usage and cost and the likely effects of swapping titles in and out of a deal, and the cost effectiveness of the deal itself. A number of data sets were used, including JUSP data (Jisc, n.d.a), Ulrich's subject headings, impact factors and cost information. Usage was explored between 2011 and 2015 and the entire COUNTER JR1 report (COUNTER, 2017) was included for the team's institution. As a result multiple platforms were explored showing aggregated usage. Several options to analyse usage, cost and impact were available including subject area, individual journal title, and a cost per use metric for a journal article download. This was available as a slider option and the user could change the threshold of the cost per use. For example, the cost of an Inter-Library Loan could be used to observe which titles were above this threshold and therefore may be better to cancel. The combination of cost per use data with impact factor provided an immediate visual impact making further analysis easier. Those titles with high cost per use combined with low impact factor were instantly identifiable, thus providing a ready cancellation list for consideration. Alternately, a slider option for impact factor was also included and could be used to focus further analysis on a smaller set of journal titles. Year on year usage correlation was also presented and showed the likeliness of continued usage, or not, for a given title, which again could be very helpful in making evidenced-based collection management decisions.

Publisher usage data over a five year period was used in another dashboard for a single institution. Looking at the collection, a Pareto chart was able to show visually that $80 \%$ of the usage in that deal came from only $22 \%$ of the titles in that collection, with each title, and its usage identifiable simply by hovering over each data point in the chart. Using the same data, but merging with core title 
information via a simple bar chart, showed that despite the three most used journals identified as core, there was also a very long tail of titles highlighting that high usage does not necessarily correspond to core title identification. This gave a quick visual indicator to those titles which should be further analysed, especially if the nature of the deal or core titles was to change.

The Jisc team explored how the use of data available at a sector wide level could be used to better inform the negotiation position of Jisc Collections with publishers. For proof of concept purposes, data for a society publisher were used. Using data from JUSP and institutional repository statistics from Jisc's Institutional Repository Usage Statistics service (IRUS-UK) (Jisc, 2017c), a fuller usage picture was plotted against 'quality' measures including impact factor, h5-index and Altmetrics. The dashboards allowed for sorting both on usage and quality measure. Results showed that there was a relationship between usage and quality measures, for example, higher usage and higher impact factor. The dashboard was repeated with the inclusion of a second society publisher in the same academic discipline. Usage data and similar trends were observed. This also allowed for comparison between two publishers with similar publication output. A second chart incorporated institution data showing a ranking of usage by institution. Further options included the ability to filter by Jisc band (Jisc Collections, 2017), as well as further identify other mission group members. Using Jisc Collections cost information, the cost and average cost per download were visualised. Crossreferencing with Jisc band data provided insight to the value that each band achieved with the deal.

Finally, building on the previous dashboard, the Jisc team created an institutional profiling dashboard. The aim was to help institutions measure their usage of journal packages against anonymised usage data from other institutions in the sector. An institution could see their performance for a given journal publisher as part of the whole picture and by Jisc Band and/or mission group.

\section{Discussion}

Data used by the projects were available on a secure server as part of the Heidi Labs project. Some of the HESA data were potentially sensitive, because of this each team member was required to sign a data protection agreement to ensure data that contained personal details was not shared outside of the project. In effect this created a walled garden as some of the data were not designed for sharing. Furthermore, the data that the Jisc team used was restricted by publisher agreements, meaning that specific institutions' usage could not be identified to others. However, dashboard visualisations that were taken forward by HESA were to be developed in a secure area. Other work could be taken on by individual libraries as part of their own library analytics programmes and by Jisc as part of its own evidence based research.

\section{Institutional implications}

The project provided many participants with their first experience of HESA data and Tableau visualisation software. Although acknowledged by participants as an excellent training opportunity, compared to other cohort members who were more familiar with both these elements, librarians faced a steeper learning curve to produce their dashboards. However, participants were at least very familiar with key data sets in their area, such as SCONUL metrics, NSS data and e-resources usage data and knew the questions that they wanted to answer.

The opportunity to work with colleagues from other libraries was also seen as a key benefit of participation, whether it was hearing about different approaches or sharing the same problems. For example, Simon Bains, Head of Research Services and Deputy Librarian, The University of Manchester, commented that, 
"Library Data Labs is a hugely worthwhile concept, with the potential to deliver a step change in data literacy and data-driven decision-making in libraries. I found it to be very rewarding to work with and learn from colleagues across the sector and to gain practical experience of agile project management and data visualisation software. This is an opportunity to contribute to national efforts to use data to answer strategically important questions about the use and impact of academic libraries".

\section{Implications for Jisc library support services}

Following the successful development of proof-of-concept dashboards from the Library Data Labs activity it was decided to fully develop a visualisation facility within a live service, JUSP. It was appropriate, given the large files being interrogated, for the data to be presented in a more compact and summarised format, more easily viewed than in tabular reports.

JUSP data are stored in a MySQL database, though with higher granularity than required in visualisations. Thus, several scripts were written to aggregate the data to a suitable level, such as total accesses per month, publisher and institution, and output to (CSV format) files on the JUSP server. These files were downloaded (via secure FTP) to a workstation running Tableau Desktop and ingested. Several visualisations for individual institutions were then created using the aggregated data, including:

- Individual publisher usage by calendar year

- Individual publisher usage by academic year

- Non-zero Gold Open Access (GOA) data by publisher and calendar year

- Calendar year usage trends per publisher (showing monthly data)

- Academic year usage trends per publisher (showing monthly data)

- Top $\{x\}$ publishers per year

- Title level visualisations such as top journals per academic and calendar year

- Turnaway data.

All visualisations were created in two Tableau workbooks with an individual dashboard for each report required. Several book data visualisations were also created as a proof of concept. Once complete these workbooks were published, via secure connection from Tableau Desktop, to a Tableau Server with the data sources, the aggregated CSV files, being embedded in the workbooks. These dashboards were subsequently made available on the JUSP website via links to the relevant sections of the workbooks on the Tableau Server.

The initial versions of the visualisations embedded on the JUSP website were made available to a select group of users, including the JUSP Community Advisory Group (CAG). The feedback was very positive and featured several suggested amendments and additions, particularly around exporting visualisations for use in local presentations or documents. These requests are currently being addressed with the aim of putting the enhanced visualisation service into production.

In addition, investigations to fully automate the update mechanism are in progress; data in JUSP change daily as new/amended usage reports are made available by providers. In the current approach the scripts to aggregate the data are scheduled to run nightly.

\section{Implications for Jisc Collections publisher negotiations}

In June 2016, Jisc Collections created a new research team whose remit was to conduct evidence based research to inform Jisc Collections licensing and negotiation activities with publishers and 
suppliers. The internal Jisc team in the Library Data Labs project therefore included staff from both JUSP and the research team.

Further to the work on visualisations allowing JUSP library users to interrogate their usage, similar work was taken forward by the research team in order to gain a greater understanding of data at a national level. Indeed, the needs of Jisc Collections at a consortia level should mirror the needs of individual institutions when assessing their own data. Therefore, lessons learned from the data cleansing in the data labs project have been used by the research team. Consortia level reports from JUSP, Knowledge Base+ (KB+), a service from Jisc Collections that aims to help UK libraries manage their e-resources more efficiently by providing accurate publication, subscription, licence and management information (Jisc, n.d.b), publisher data and institutional spend data (where available) were used to create visualisations for the Jisc Collections licensing and negotiations team. Since the summer of 2016, these visualisations have been used in a number of high level journal negotiations and other reports. For example, a report on the first year of the Springer Compact agreement used visualisations to demonstrate the impact of the agreement to participating institutions (Marques, 2017).

\section{Further work}

Libraries are information and data centres like few others, both by the nature of their business and through the data they collect. However, with so much information, it is not easy to make effective use of the data they possess given increasingly limited time and resources. Therefore it was timely that the Library Data Labs provided opportunities for UK libraries to advance their analytics efforts.

Since completion of the project, HESA have reviewed all the dashboards and concluded which of these can be taken forward to service based on whether a proof of concept dashboard was scalable and robust enough for a national platform, such as HESA's Heidi -Plus in terms of live data. As a result, four of the 19 dashboards produced by the cross-institutional teams will be available during 2017. A new cohort of libraries are developing further dashboards building on the Library Data Labs outputs and also the LIDP and LAMP projects. Early aims of this cohort are to explore any trends over time between the various SCONUL metrics relating to any student engagement with libraries and NSS scores, and also impact of any financial investment.

Jisc's JUSP service will also be taking forward the institutional profiling dashboard as an additional offering within the service in 2017. A potential requirement for a Jisc shared service to house nonHeidi Plus dashboards has also emerged. This would provide a route to data contributed by institutions and from Jisc services.

In parallel, Jisc's Learning Analytics initiative has started to address the collection of basic library interaction events such as logins, borrowing and accessing content. This is being carried out with a number of library systems providers to investigate direct extraction of such data, and automated submission into learning records data warehouses. Jisc's learning records warehouse already houses data regarding the usage of other systems such as virtual learning environments (VLEs) and attendance monitoring systems, as well as student demographic and attainment data.

As Oakleaf (2010) suggests, there are no "quick fixes" or "simple solutions to the challenge of articulating academic library value". This paper has shown that there is continuing appetite for new library analytics developments. This suggests a continued demand amongst libraries to provide evidence of their value to their own institutions and also a need to improve service offerings in line with user demands. It is hoped that by providing a series of dashboards at a national level, libraries 
will be able to look at their own data in a consistent and granular way. This will allow libraries to ask further questions using more qualitative methods and effect decisions to improve user experience.

References

Barkey, P. (1965), "Patterns of student use of a college library", College \& Research Libraries, Vol.26 No.2, pp. 115-118. Available at: http://dx.doi.org/10.5860/crl 2602115 (Accessed 19 April 2017).

Bowles-Terry, M. (2012), "Library instruction and academic success: a mixed-methods assessment of a library instruction program", Evidence Based Library and Information Practice, Vol.7 No.1, pp. 8295. Available at: https://ejournals.library.ualberta.ca/index.php/EBLIP/article/view/12373 (Accessed 19 April 2017).

Collins, E. \& Stone, G. (2014), "Understanding patterns of library use among undergraduate students from different disciplines", Evidence Based Library and Information Practice, Vol.9 No.3, pp. 51-67. Available at: http://ejournals.library.ualberta.ca/index.php/EBLIP/article/view/21326 (Accessed 19 April 2017).

Cox, B. \& Jantti, M. H. (2012), “Capturing business intelligence required for targeted marketing, demonstrating value, and driving process improvement", Library and information science research, Vol.34 No.4, pp. 308-16. Available at: http://dx.doi.org/10.1016/j.lisr.2012.06.002 (Accessed 19 April 2017).

COUNTER (2017), "Usage reports", available at: https://www.projectcounter.org/code-of-practicesections/usage-reports/ (Accessed 15 August 2017).

De Jager, K. (2002a), "Impacts and outcomes: searching for the most elusive indicators of academic library performance", in Meaningful measures for emerging realities, proceedings of the 4th Northumbria International Conference on Performance Measurement in Libraries and Information Services. Association of Research Libraries, Washington, DC, pp.291-297. Available at: http://www.libqual.org/documents/admin/4np secure.pdf (Accessed 19 April 2017).

De Jager, K (2002b), "Successful students: does the library make a difference?" Performance measurement and metrics, Vol.3 No.3, pp. 140-144. Available at: http://dx.doi.org/10.1108/14678040210453564 (Accessed 19 April 2017).

De Jager, K. (2017), "Approaches to impact evaluation in academic libraries: a review of a new ISO standard", IFLA journal, Available at: http://dx.doi.org/10.1177/0340035217696321 (Accessed 19 April 2017).

De Jager, K., Nassimbeni, M., Daniels, W. \& D'Angelo, A. (2017), “The use of academic libraries in turbulent times: student library behaviour and academic performance at the University of Cape Town", paper presented at the 12th International Conference on Performance Measurement, 31 July-2 August 2017, Oxford, UK.

Emmons, M. and Wilkinson, F.C. (2011), "The Academic library Impact on student persistence", College \& Research Libraries, Vol.72 No.2, pp. 128-149. Available at: http://dx.doi.org/10.5860/crl74r1 (Accessed 19 April 2017).

Han, S., Wong, R. \& Webb, T.D. (2011), "Uncovering meaningful correlation between student academic performance and library material usage", College \& Research Libraries, Vol.72 No.4, pp. 361-370. Available at: http://dx.doi.org/10.5860/crl-129 (Accessed 19 April 2017). 
HEFCE (2017), "Teaching Excellence Framework (TEF)", available at: http://www.hefce.ac.uk/lt/tef/ (Accessed 27 April 2017).

HESA (n.d.a), "Heidi Plus: Higher education business intelligence", available at: https://www.hesa.ac.uk/services/heidi-plus (Accessed 29 April 2017).

HESA (n.d.b), "JACS", available from: https://www.hesa.ac.uk/support/documentation/jacs (Accessed 27 April 2017).

Jisc (n.d.a), "Journals Usage Statistics Portal”, available at: http://jusp.jisc.ac.uk/ (Accessed 27 April 2017).

Jisc (n.d.b), "Knowledge Base+", available from: https://www.kbplus.ac.uk/kbplus/ (Accessed 3 May 2017).

Jisc (2011), "Jisc activity data", available at:

https://www.webarchive.org.uk/wayback/archive/20140614021552/http://www.jisc.ac.uk/whatwe do/programmes/inf11/activitydata.aspx (Accessed 27 April 2017).

Jisc (2017a), "Business intelligence project", available at:

https://www.jisc.ac.uk/rd/projects/business-intelligence-project (Accessed 19 April 2017).

Jisc (2017b), "Effective learning analytics", available at: https://www.jisc.ac.uk/rd/projects/effectivelearning-analytics (Accessed 19 April 2017).

Jisc (2017c), "IRUS-UK", available at: http://www.irus.mimas.ac.uk/ (Accessed 15 August 2017).

Jisc Collections (2017), "Jisc banding model", available at: https://www.jisc-collections.ac.uk/Helpand-information/JISC-Banding/ (Accessed 15 August 2017).

Johnson, R. K., \& Luther, J. (2007), The E-only tipping point for journals: what's ahead in the print-toelectronic transition zone, Association of Research Libraries, Washington, DC. Available at: http://www.arl.org/storage/documents/publications/electronic transition-2007.pdf (Accessed 19 April 2017).

Kramer, L. A. \& Kramer M. B. (1968), "The college library and the drop-out", College and Research Libraries, Vol.29 No.4, pp. 310-12. Available at: http://crl.acrl.org/content/29/4/310 (Accessed 19 April 2017).

Mann, P.H. (1974), Students and books, Routledge and Keegan Paul, London.

Marques, M. (2017), "Springer Compact agreement: first year evaluation", available at:

https://scholarlycommunications.jiscinvolve.org/wp/2017/03/06/compact-agreement-first-yearevaluation/ (Accessed 29 April 2017).

Nackerud, S., Fransen, J., Peterson, K. \& Mastel, M. (2013), “Analyzing demographics: assessing library use across the institution, portal: libraries and the academy, Vol.13 No.2, pp. 131-145.

Available at:

http://www.press.jhu.edu/journals/portal libraries and the academy/portal pre print/current/ar ticles/13.2nackerud.pdf (Accessed 19 April 2017).

Oakleaf, M., Stone, G., Pattern, D., Bowles-Terry, M., Peterson, K., Nackerud, S. \& Fransen, J. (2013), "Do or do not...there is no try: the quest for library value", paper presented at Association of College 
\& Research Libraries Conference, 10-13 April 2013, Indianapolis, IN. Available at: http://eprints.hud.ac.uk/16421/ (Accessed 19 April 2017).

Oakleaf, M., Fransen, J., Nackerud, S., Peterson, K., Maclntyre, R., Sharman, A. \& Krieb, K. (2017), "Data in the library is safe, but that's not what data is meant for: exploring the longitudinal, responsible use of library and institutional data to understand and increase student success", paper presented at Association of College \& Research Libraries Conference, 22-25 March 2017, Baltimore, MD.

Oakleaf, M. (2010), The value of academic libraries: a comprehensive research review and report, Association of College and Research Libraries, Chicago.

Poll, R. (2012), "Can we quantify the library's influence? Creating an ISO standard for impact assessment", Performance measurement and metrics, Vol.13 No.2, pp. 121-130. Available at: http://dx.doi.org/10.1108/14678041211241332 (Accessed 19 April 2017).

Poll, R. \& Payne, P. (2006), "Impact measures for libraries and information service", Library Hi Tech, Vol.24 No.4, pp. 547-562. Available at: http://dx.doi.org/10.1108/07378830610715419 (Accessed 19 April 2017).

SCONUL (2017a), "National Student Survey (NSS) Data”, available at:

https://www.sconul.ac.uk/page/national-student-survey-nss-data (Accessed 27 April 2017).

SCONUL (2017b), "SCONUL statistics", available at: https://www.sconul.ac.uk/tags/sconul-statistics (Accessed 27 April 2017).

Sharman, A. (2017), "Using ethnographic research techniques to find out the story behind international student library usage in the Library Impact Data Project", Library management, Vol.38 No.1, pp. 2-10. Available at: http://dx.doi.org/10.1108/Im-08-2016-0061 (Accessed 19 April 2017).

Showers, B. (2015a), "Introduction: getting the measure of analytics and metrics", Showers, B., Library analytics and metrics: using data to drive decisions and services, Facet, London, pp. xxv-xxxi.

Showers, B. (2015b), "Library big data: developing a shared analytics service for academic libraries", Showers, B., Library analytics and metrics: using data to drive decisions and services, Facet, London, pp. 14-20.

Showers, B. \& Stone, G. (2014), "Safety in numbers: developing a shared analytics service for academic libraries", Performance measurement and metrics, Vol.15 No.1/2, pp. 13-22. Available at: http://dx.doi.org/10.1108/PMM-03-2014-0008 (Accessed 19 April 2017).

Soria, K., Fransen, J. \& Nackerud, S. (2013), "Library use and undergraduate student outcomes: new evidence for students' retention and academic success", portal: libraries and the academy, Vol.13 No.2, pp. 147-164. Available at:

http://www.press.jhu.edu/journals/portal libraries and the academy/portal pre print/current/ar ticles/13.2soria.pdf (Accessed 19 April 2017).

Stone, G. \& Collins, E. (2013), "Library usage and demographic characteristics of undergraduate students in a UK university", Performance Measurement and Metrics, Vol.14 No.1, pp. 25-35. Available at: http://dx.doi.org/10.1108/14678041311316112 (Accessed 19 April 2017).

Stone, G. \& Ramsden, B. (2013), "Library Impact Data Project: looking for the link between library usage and student attainment", College \& Research Libraries, Vol.74 No.6, pp. 546-559. Available at: http://dx.doi.org/10.5860/crl12-406 (Accessed 19 April 2017). 
Stone, G., Sharman, A., Dunn, P., \& Woods, L. (2015), "Increasing the impact: building on the Library Impact Data Project", Journal of academic librarianship, Vol.41 No.4, pp. 517-520. Available at: http://dx.doi.org/10.1016/j.acalib.2015.06.003 (Accessed 19 April 2017).

White, S. \& Stone, G. (2010), "Maximising use of library resources at the University of Huddersfield", Serials, Vol.23 No.2, pp.83-90. Available at: http://dx.doi.org/10.1629/2383 (Accessed 19 April 2017). 